\title{
The Impact of Cloud Computing on the Quality Of E-learning at Tabuk University
}

\author{
Dr . Nedal Hassen Elbadowi Eljaneid
}

Assistant Profeessor . Pure Mathematic Tabuk University

drnedaaleljaneid@yahoo.com 


\title{
The Impact of Cloud Computing on the Quality Of E-learning at Tabuk University
}

\author{
Dr . Nedal Hassen Elbadowi Eljaneid \\ Assistant Profeessor . Pure Mathematic Tabuk University \\ drnedaaleljaneid@yahoo.com
}

\begin{abstract}
:
The study aimed at identifying the concept of cloud computing and explaining the benefits of using cloud computing in the educational process and understanding the impact of the application of cloud computing on the quality of e-learning in developing mathematical knowledge and skills among university students, the study used the semi-experimental approach, and the study sample consisted of a group of female students of the year Preparatory at the University of Tabuk during the academic year 1438/1439 $\mathrm{AH}$, and the results of the study indicated the effectiveness of cloud computing in developing mathematical achievement and developing skills related to mathematics for university students, and the study provided a set of recommendations Research and proposals to increase the use of cloud computing at the University of Tabuk.
\end{abstract}

Keywords:Cloud Computing , Quality of E-learning , University ofTabuk

\begin{tabular}{|c|c|}
\hline ديسمبر 9 1 • r & $-2-$ \\
\hline
\end{tabular}




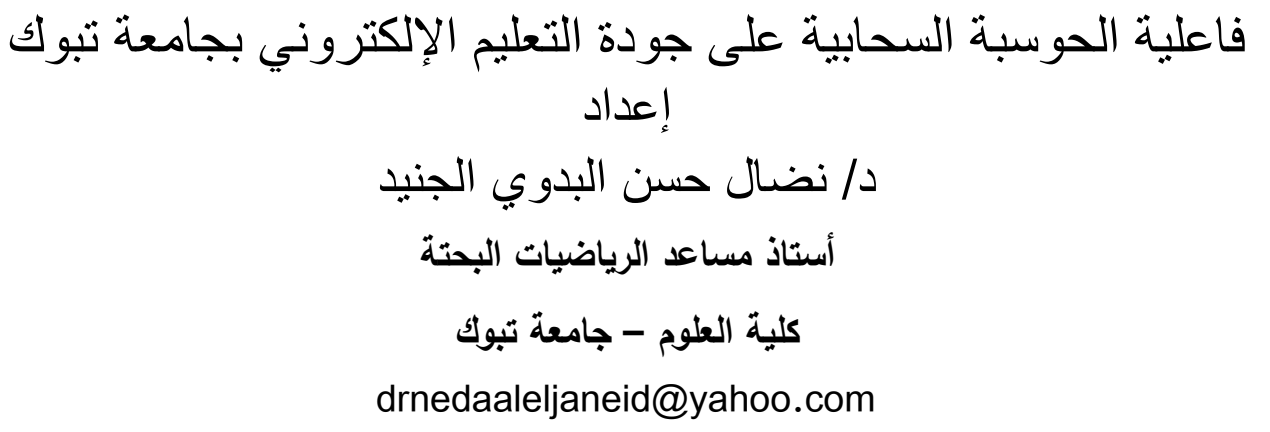

المستخلص:

هدفت الدراسة إلى التعرف على مفهوم الحوسبة السحابية وتوضيح فوائد استخدام الحوسبة السحابية في العملية التعليمية وفهم تأثثر تطبيق الحوسبة السحابية على جودة التعليم الإلكتروني في تتمية المعرفة والمهارات الرياضية لدى طالبات الجامعة ، وقد إستخدمت الدراسة المنهج شبه التجريبي ، وقد تكونت عينة الدراسة من مجموعة من طالبات السنة التحضيرية بجامعة تبوك خلال العام الجامعى 1438/1439 هـ ، وقد أثنارت نتائج الدراسة إلى فاعلية الحوسبة السحابية فى تتمية التحصيل الرياضى وتتمية المهارات المتعلقة بمادة الرياضيات لاى طالبات الجامعة ، وقدمت الدراسة مجموعة من التوصيات والبحوث المقترحة لزيادة إستخدام الحوسبة السحابية فى جامعة تبوك . الكلمات المفتاحية :الحوسبة السحابية ، جودة التعليم الإلكتروني ، جامعة تبوك 
1. Introduction : Cloud computing is a sophisticated technology that relations on the transfer of processing and storage space of the computer to the so-called cloud, a server that is accessed through the Internet, transforming IT programs from products to services. Computing, applications and even operating systems cloud have provided infrastructure, services, and software through a network. This network offers attractive benefits to higher education institutions with the ability to reduce ICT costs through virtualizing capital expenditures that install more than one operating system (Windows-Mac-Linux-Others) in a virtual environment within the current operating system to enable experience system like the rest of the programs are browsing at anytime.

1.2 Purposes of the Study: This research aims at introducing the concept of cloud computing and clarifying the benefits of employing cloud computing in the educational process and understanding the effect of applying cloud computing on the quality of E-learning in enhancing the knowledge and the skilled side of the preliminary students in a mathematicsdepartment.

1.3 Methodology of the Study: To achieve the research objectives, the detailed approach and the semi-experimental approach are used to suit the current research objectives.

1.4 Significance of the Study: The importance of this research in several parts:

The oreticalpart:

(1) This study corresponds with the attention of officials at the

Ministry of Education in the Kingdom of Saudi Arabia E - training a new challenge For university training.

(2) The scarcity of the Arab study, which dealt with the subject ofcloud

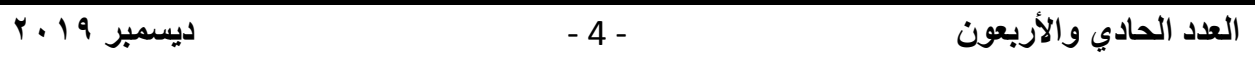


computing and its applications in the field of universityeducation.

Applied part:

(1) The use of study may contribute to increasing the academicachievement of the students of the preparatory year in the mathematicsdepartment.

(2) The results of this study may help to encourage researchers to conduct further studies in thisfield.

1- 5 Population of the Study : Students of the preparatory year, Mathematics Department, Faculty of Science, Tabuk University 969student

1-6 Sample of the Study: A group of students in the preparatory year for summer separation recorders in 1438/1439AH

1-7 Hypotheses of the Study :

- There were no statistically significant differences at level $(\alpha=0.05 \%)$ between the mean scores of the pre-test and the post-test cognitive achievement

- There were no statistically significant differences at the level of $(\alpha=$ $0.05 \%$ ) between the mean scores of the pre-test and thepost-skill.

1-8 Terminology of Study : Cloud Computing: Know both Hussein and Sumaidai (2012):

"A new model is to pay as much as use to access hardware and

The US National Institute of Standards and Technology defines cloud computing as a model for enabling end-to-end network access and sharing a range of computing resources (server networks, storage units, applications and services) that can be quickly deployed and delivered with an effort by management or Interaction with the service provider"( Mell \& Grance , 2011).

The e-learning: the delivery of learning and education program through

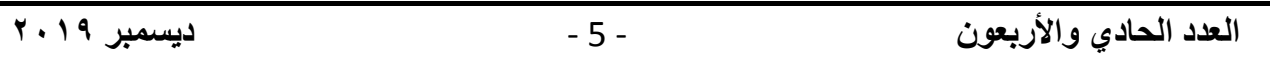


electronic means and includes e-learning to use a computer or any other electronic device to provide training or educational materials.

- Al-Awaid and Al-Hamed $(1424 \mathrm{H})$ define e-learning as an education that aims to create a rich interactive environment with computer-based applications and enables students to access learning resources anytime, anywhere.

- An educational system to provide educational or training programs for learners or trainees at anytime and anywhere to useinteractive information and communication technologies to offer a multi-source interactive learning/learning environment synchronously orasynchronously.

2 . General Concepts: The era in which we live with our various needs is characterizedbyrapidprogress.Today, scienceiswitnessingacleardevelopment in the various scientific and technical fields. Superior technology has imposed itself in multiple areas of life. Technological progress has led to the emergence of new methods of education. Techniques are based on the use of technological innovations to achieve the required knowledge and seek new ways, systems, modelsandteachingaidstoaddressmanychallengesatthegloballevel,including increased demand for education, a shortage of educational institutions and an increase in the amount of information in all branches of knowledge for recent trends in mathematicseducation.

2.1 The Concept of Cloud Computing : Refers to the on-demand computer resources and systems available on the network that can provide several integratedcomputerserviceswithoutlocalresourcestofacilitatetheuser.These resources include space for data storage, backup and self-synchronization and consists of the capabilities of software processing and scheduling of tasks and payment of mail Electronic and remote printing. When connected,
ديسمبر 9 ب 19
$-6-$
العدد الحادي والأربعون 
the user can control these resources with a simple software interface that simplifies and ignores many internal details and processes [1] The concept of cloud computing has been defined as "a technology that relies on the transfer of processing and storage space of the computer to the so-called cloud, a server that is accessed throughtheInternet.Thisturnstechnologyprogramsprovidelargestoragespace forusersanditprovidessomeprogramsasservicesUsersrelyonthepossibilities provided by Web technologies 2.0 [2]. This can be illustrated by Figure(1) The idea of cloud computing Cloud Computing :

Figure (1) : Called cloud computing or cloud computing C. C

2.2 Components of cloud computing [3] Cloud Computing:

1. Applications : Are programs and services that can be occupied by the client in the cloud, and with service Software As a Service the maintenance and development burden of the user has been reduced.

2. Client : Is the user, who uses his equipment (whether mobile or computer or the iPad to benefit from the service, and may have a system that supports the cloud or Browser is used only .

3. Infrastructure : Is the cloud infrastructure, which is provided as a service Infrastructure as a service.

4 . Platform: Is the platform you use in the cloud, such as Python Django, Java Google Web Toolkit In Google .

\begin{tabular}{|c|c|}
\hline ديسمبر 9 1 ـ r & $-7-$ \\
\hline
\end{tabular}


The Impact of Cloud Computing on the Quality Of E-learning at Tabuk University Dr . Nedal Hassen Elbadowi Eljaneid

5- Service : Is the service you use on the cloud, and the subject

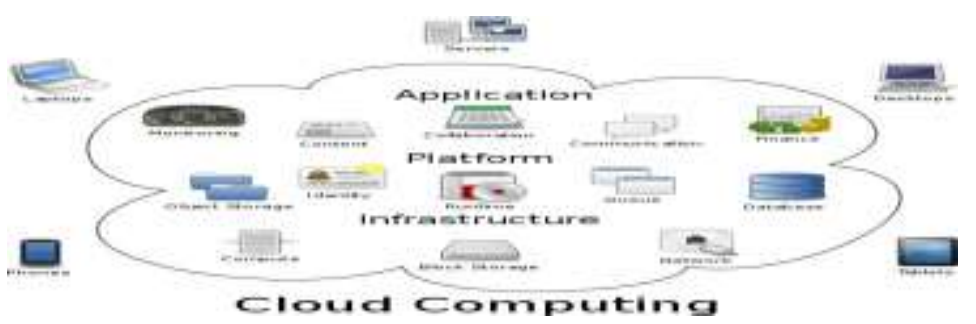

is more concerned with the term Software as a Service, Is the process of converting computer products into services .

Figure (2)

\section{2-3 Cloud Computing Models:}

1. A public cloud: Are available to the general public and are commercially based and are usually owned by companies selling cloud services.

Private Cloud : They are private networks for certain entities that provide full data control, security and data quality.

2 . Common Cloud: many organizations or ministries who share a similar interest in service share Cloud infrastructure.

3. Hybridcloud:Cloudinfrastructurehasavehicleoftwoormoreclouds(private, community,orpublic)thatareassociatedwithstandardorparticulartechnology enabling it to allow data or applications to be transferred from one cloud to another.

2.4 Benefits of employing cloud computing in the learningprocess:Cloud computing is one of the most modern forms of virtualization software widely used in the business, service and e-government sectors in most of the world. Recently it has been introduced as an idea for use in the fields of distance learning and E-learning, Cloud ( Computing It is no longer just a theoretical concept but turned into a concrete application we see in a number of communal servicesintheweb,especiallyinthefieldofe-

العدد الحادي والأربعون


The Impact of Cloud Computing on the Quality Of E-learning at Tabuk University

Dr . Nedal Hassen Elbadowi Eljaneid

learning,forexample,ithasmoved.

(1) Buildingtestsofsoftwarethatcanbedownloadedtothedevicetoserviceson the Internet does not require any operation Special software to take advantage of, site classmarker.com) And service (quiz-school) For example, they have taken advantageofcloudcomputingcapabilitiestoofferthetesthostingandevaluation servicesautomaticallyforfreeoratanominalprice. Thesitesofferthepossibility of running tests of various types such as complete the vacuum, Multiple choice, correct and error, etc., with the potential to display questions randomly or in a particular order, and publish the test by e-mail or webpages.

(2) Provided Google A dedicated system in scheduling the course under the name(CloudCourse)Thesystemallowsteacherstocreateandfollowuplearning activities, schedule, manage and approve the queue, in addition to advanced features such as table synchronization with compatible systems, room information service and finally user information service [4].

(3) Cloud computing fosters collaboration between learners, teachers, and others inacademia.

(4) It is easy for the teacher to propose modifications by accessing the student

fileinthecloud,savehiscomments, andnotifythestudentthroughthesystem.

(5) Benefit from the vast infrastructure provided by the cloud services to carry out scientific tests andexperiments.

2.5 Beauties of CloudComputing:

1. User-centered: Once the user has connected to the cloud, whatis stored there becomes documents, messages, images, applications, or whatever the

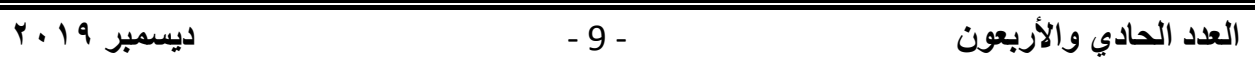


user. It is not only for the user but also for sharing with others.

2. With a central mission: Instead of focusing on what can bedone and what can be done, the focus is on what the user needs to do, and how the application can do it for him.

3. Powerful : It connects hundreds or thousands of computersin thecloud.

4. Access:Dataisstoredinthecloudanduserscaninstantlyrecovermore information from multiple repositories and not just one source of data as was the case withcomputers.

5. Smart: extracted and analyzed data to access this information intelligently.

6. Programmed:Manyofthenecessarytaskswithcloudcomputingmust be automated, for example, to protect the integrity and storage of data on one computer in the cloud must be copied on other machines in the cloud if this computer has moved to Outside the grid, the cloud automatically reprograms from that computer to another new equipment in thecloud.

2-6 Models of Cloud Services :

2.6.1 Service Google Cloud Drive : One of the recent cloud services of Google,

whichhasbecomeaglobalechoandextensiveapplicationsbyresearchersand information institutions. This service appeared in April of this year 2012, Which allows the user to store the various files on the main servers inGoogle.

Features Google drive : Google Cloud Drive has many features and features :

1. Itis a cloud service belonging to a large international company that has a reputation in the field of the Internet through the global community. 
The Impact of Cloud Computing on the Quality Of E-learning at Tabuk University Dr . Nedal Hassen Elbadowi Eljaneid

2. Google provides the user with the ability to store their files throughthe availability of storage capacity in Google drive this storage capacity reaches 15th Free Gigabyte Available to thebeneficiary.

3 . The great power of the company's servers Google which ensures the possibility of uploading user files onthem.

4 . Service Integration Google drive With other services Google, Where available services can be easilynavigated.

5 . Provides many services such as storage, sharing, downloading, editing, and saving of files andmore.

6 . Features include automatic spell checking, Correcting all the errors thatare available in thelist.

7 . Updates and features are added every period on Google drive.

8 . The possibility of sharing work by forming groups on Google drive.

9. Option to load Google drives On many type of hardware computers, phones, tablets.

10. The possibility of cloud storage of any kind of files and access to them atany time andplace.

11. There are multiple features such as automatic file preservation and software support such as Photoshop and PowerPoint.

2.6.2 Service Drop Box : is an external site hosting files and has many benefits and advantages. It provides a user-specific cloud service on the Internet that allows it to freely store data and also synchronize its various files between different devices and various modern media. When you install a program(Drop Box)Theprocessofrealstorageonaremoteserversymbolizes (cloud) allows the user to add and modify and change the files through the media available to him and that enables him to use the programDrop Box. 
The Impact of Cloud Computing on the Quality Of E-learning at Tabuk University Dr . Nedal Hassen Elbadowi Eljaneid

Advantages of using a service Drop Box Cloud : This service offers many advantages to the beneficiaries:

1. Enables the user to view and browse his files and modified from which place In any geographical area provided that the Internet service isavailable.

2. Save files for fear of loss, loss or damage Of personal devices and thus can be retrieved at any time.

3. In order to share files among people The relationship and ease of use even as the working environments are different and can send a link to files on the mail of people Concerned.

4. If you run out of storage space on a user's computer, This program will quickly send a link to files on the mail of the persons concerned.

5. Allows to upload and store various types of documents, images and other applications Files.

6. Easy The process of taking pictures and synchronizing with the program (Drop Box ) At the same moment.

7. Copy or paste the image links directly into theclipboard.

8. Review Office files and documents pdf And others without the needfor any additional software.

9. It supports Arabic language files and otherlanguages.

10. Synchronize audio and video files directly with (Drop Box ) and also operated.

11. The location of Drop Box the user has a free space of 2 This space canbe increased by a monthly fee 50 Giga or 100Giga.

12. Opium devices allow the user the freedom to create a private secretcode for additional confidentiality.

13. Uploadfilestoyoursmartphoneandrunthemdirectlywithouttheneedof the Internet.

2.6.3 :Google Drive: The service offered by the company provides more 
The Impact of Cloud Computing on the Quality Of E-learning at Tabuk University Dr . Nedal Hassen Elbadowi Eljaneid

storage space than other services can be used by Space up to $15 \mathrm{~kb}$ as Allows you to process And modify your files online without having to have the modification software installed on your computer. This application is utilized Decrypt and transfer compressed files from computer to iPad :

2-6- 4 I zip Application :In lectures pressure course for ease of transmission processes for students and jaw.

2-6-5program Explain Everything:Is an easy-to-use tool that gives you an interactive whiteboard that enables you to do the program can be defined on iPhone and iPad There is a free version and a paid version and is used in this research applied to explain sports and sports equations Program Features :

1. Action Animation and Writing Handles ..

2. Export all media files and share them asmovies

3. Add videos / photos, presentations and audio recordings.

4. The possibility of moving objects from one place to another.

3. Procedures ofResearch:

3.1 StudyTools: The researcher used a toolkit to answer research hypotheses such as :

3.1.1 : Statistical analysis Spss:To find the statistical differences between the two averages Pre-test and post-test cognitive achievement. 3.1.2 : Machine T1-nsipre To measure the statistical differences between the two averages Pre - and post - test for the empirical test of the theoretical side. 
The Impact of Cloud Computing on the Quality Of E-learning at Tabuk University Dr . Nedal Hassen Elbadowi Eljaneid

Answer the First question :There were no statistically significant differences at level $(\alpha=0.05 \%)$ between mean scores Pre-test and posttest cognitive achievement :

paired-Sample Statistics

\begin{tabular}{|l|l|l|l|l|}
\hline & $\mathrm{N}$ & Mean & Std. Deviation & Std. Error Mean \\
\hline pre & 65 & 7.6462 & 3.42979 & 0.42541 \\
post & 65 & 16.4769 & 4.17623 & .51800 \\
\hline
\end{tabular}

paired-Sample Test

\begin{tabular}{|c|c|c|c|c|c|c|}
\hline & \multicolumn{6}{|c|}{ Test Value $=05$} \\
\hline & \multirow[t]{2}{*}{$\mathrm{T}$} & \multirow[t]{2}{*}{ Df } & \multirow{2}{*}{$\begin{array}{l}\text { Si. G } \\
(2- \\
\text { tailed })\end{array}$} & \multirow[t]{2}{*}{$\begin{array}{l}\text { Mean } \\
\text { Difference }\end{array}$} & \multicolumn{2}{|c|}{$\begin{array}{l}95 \% \text { Confidence } \\
\text { Interval of the } \\
\text { Difference }\end{array}$} \\
\hline & & & & & Lower & Upper \\
\hline Pre & 6.220 & 64 & .000 & 2.64615 & 1.7963 & 3.4960 \\
\hline Post & 22.156 & 64 & .000 & 11.47692 & 10.4421 & 12.5117 \\
\hline
\end{tabular}

There is a statistically significant mean for the pre-test as well as for the post-test and the result has been highly significant now $p=0.000$.

\begin{tabular}{|l|c|c|c|c|}
\hline \multicolumn{5}{|c|}{ Distribution of pre - and post - test scores on female sample } \\
\hline The stairs of & less than 12 & $19-13$ & $25-20$ & The success rate \\
\hline Tribal Test & 58 & 7 & 0 & $10.77 \%$ \\
\hline Post-test & 11 & 37 & 17 & $83.10 \%$ \\
\hline Total & 65 & \multicolumn{5}{l}{} \\
\hline
\end{tabular}



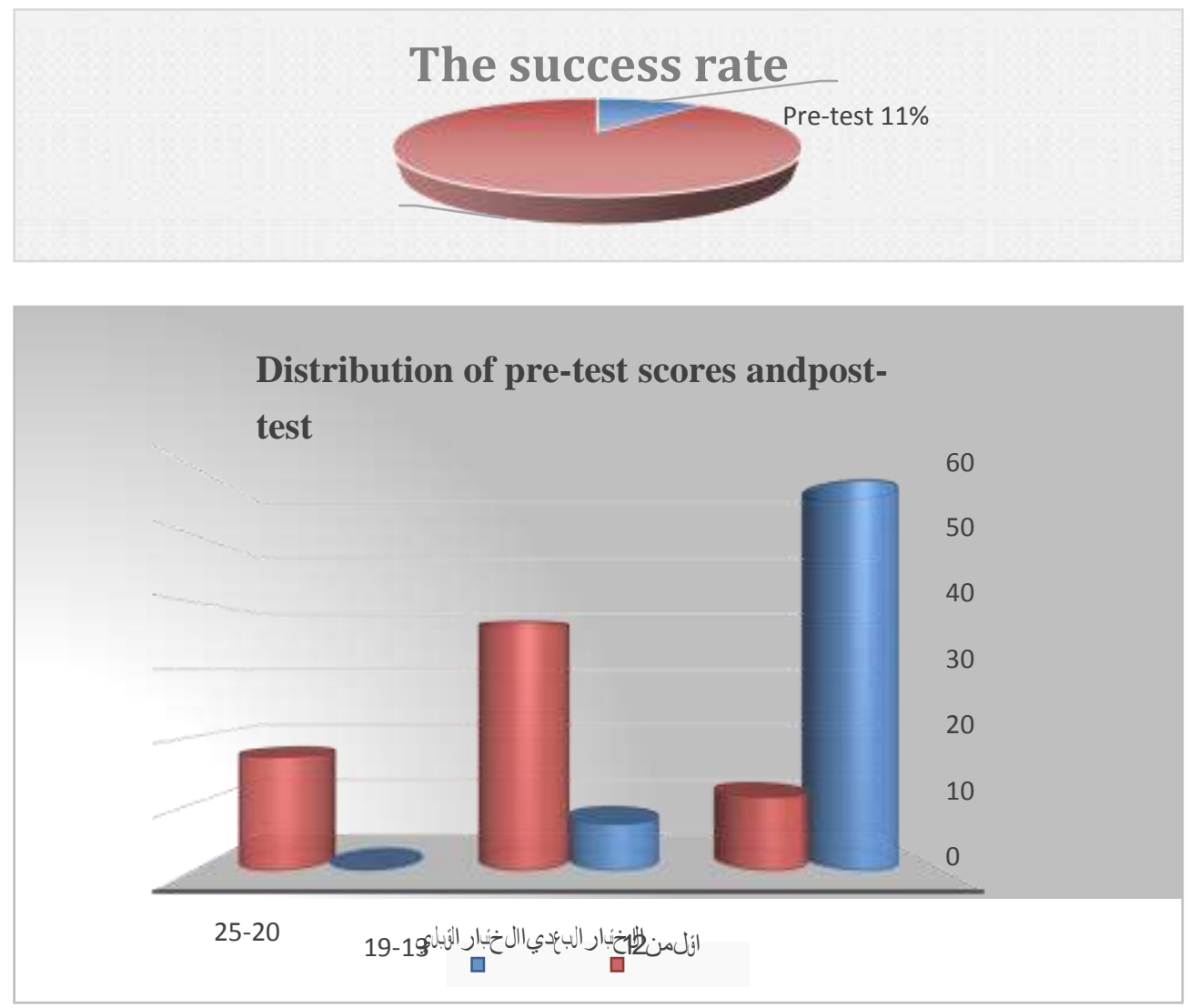

From the analysis of the result of the tribal and post-test of the students, the research found significant differences at the level of $(\alpha=0.05 \%)$ between intermediate scores Pre-test and post-test cognitive achievement

\section{Answer the second question:}

There are no statistically significant differences at the level $(\alpha=0.05 \%)$ between the arerage scores of the pre-test and the post-skill.To answer this question, the researcher used a technique T1-nsipre Explanation of the application of the graph: An application that enables the drawing of functions, equations (rectum, parabola, circle, ellipse, extra cutting, and conical sections), parametric and polar functions, 
The Impact of Cloud Computing on the Quality Of E-learning at Tabuk University Dr . Nedal Hassen Elbadowi Eljaneid

\section{Summary of Conclusion results:}

- There are significant differences at the level of $\alpha=0.05 \%$ between the are rage scores of the pre-test and the post-test cognitive achievement.

- There are significant differences at the level of $\alpha=0.05 \%$ between the are rage scores of the pre-test and thepost-skill.

- The use of computer cloud helps to increase the academicachievement of students of the preparatory year in the mat hem .

- Use of purification T1-nsipre With the computer cloud contributes to the development of the skilled side of the students of the preparatory yearin the Department ofMathematics. 
The Impact of Cloud Computing on the Quality Of E-learning at Tabuk University

Dr . Nedal Hassen Elbadowi Eljaneid

\section{References:}

Abou El Nasr M ( 2015 ), Total Quality Management Kaizen Japanese Strategy in Developing Organizations ,, Arab Group for Training and Publishing, Cairo, Egypt,

Ahmadi, O and Abdullah R (2012), Cloud computing and e-quality in the educational process, International Conference on Digital InformationTechnology, Modern Trends in Information Technology, Jordan, Oman .

Ahmed Salem, Educational Technology and Tools, Al-Rashed Library, Riyadh 2004 M.

Ahmed,Z (2016 ) , Omari, Aisha Bilish Mohammed, Quality Standards in Distance Learning and e-Learning, Al-Rashed Library . Al- Faqi , M ( 2013 ) , Cloud Computing Among the fears and hopes ,elearning magazine Mansoura University,

Chilton S and, Mohamed S (2014), cloud computing Clued Computing Between Understanding and Application, Journal of e-Learning, Issue (11). Chloe, Sabah Mohammed, Cloud computing, its concept and applications in librariesandinformationcenters,DepartmentoflnformationStudies,SultanQaboos University.

Hussein , L ., Saadallah, A and Sumaidaie, A. ( 2012 ), The development of Mesopotamia applications of general cloud computing in organizations, a proposed model for Iraqi educational organizations, 11 ( 34),

Mohamed, H ( 2017 ) Teaching and Learning Mathematics in NonTraditional Methods, Al-Rashed Library .

Rajkumar , B (2009) . Market-Oriented Cloud Computing: Vision, Hype, and Reality for Delivering IT Services as Computing Utilities.- Rajkumar Buyya , Chee Shin Yeo, SrikumarVenugopal . - Manjrasoft Pty Ltd: 
The Impact of Cloud Computing on the Quality Of E-learning at Tabuk University

Dr . Nedal Hassen Elbadowi Eljaneid

Australia,.

Rizk, M (2013 ), Cloud computing and mobile technologies : The most prominent security strategies

Roy Tennant. "Libraries in the Cloud" online posting , (19 Feb 2010)_ http://lists.ala.org/wws/arc/lita-I . Lizhe Wang \& Gregor von Laszewski . op. cit.

Study of Alshaya, Hessa Mohammed and Alwaid, Afnan Abdulrahman, use Google Plus social network ( Google+ ) In project-based learning for PrincessUniversitystudents and their satisfaction with them, International Specialized Educational Journal, vol. 4 ), the number ( 1 ), January 2015 . Talal , H (2012 ) , Others, E-Learning (Contemporary Technology ... and Contemporary Technology), Dar Al-Iman Library .

Tareq , A (2015 ) . E-Learning and Virtual Education (ContemporaryGlobal Trends), Arab Group for Training and Publishing, Cairo, Egypt, 